\title{
Titanocene / cyclodextrin supramolecular systems: a theoretical approach
}

\author{
Adrian Riviş ${ }^{1}$, Nicoleta G Hădărugă ${ }^{1}$, Zeno Gârban ${ }^{1}$ and Daniel I Hădărugă ${ }^{2 *}$
}

\begin{abstract}
Background: Recently, various metallocenes were synthesized and analyzed by biological activity point of view (such as antiproliferative properties): ruthenocenes, cobaltoceniums, titanocenes, zirconocenes, vanadocenes, niobocenes, molibdocenes etc. Two main disadvantages of metallocenes are the poor hydrosolubility and the hydrolytic instability. These problems could be resolved in two ways: synthetically modifying the structure or finding new formulations with enhanced properties. The aqueous solubility of metallocenes with cytostatic activities could be enhanced by molecular encapsulation in cyclodextrins, as well as the hydrolytic instability of these compounds could be reduced.

Results: This study presents a theoretical approach on the nanoencapsulation of a series of titanocenes with cytotoxic activity in $\alpha-, \beta-$, and $\gamma$-cyclodextrin. The HyperChem 5.11 package was used for building and molecular modelling of titanocene and cyclodextrin structures, as well as for titanocene/cyclodextrin complex optimization. For titanocene/ cyclodextrin complex optimization experiments, the titanocene and cyclodextrin structures in minimal energy conformations were set up at various distances and positions between molecules (molecular mechanics functionality, MM +). The best interaction between titanocene structures and cyclodextrins was obtained in the case of $\beta$ - and $\gamma$-cyclodextrin, having the hydrophobic moieties oriented to the secondary face of cyclodextrin. The hydrophobicity of titanocenes (logP) correlate with the titanocene-cyclodextrin interaction parameters, especially with the titanocene-cyclodextrin interaction energy; the compatible geometry and the interaction energy denote that the titanocene/ $\beta$ - and $\gamma$-cyclodextrin complex can be achieved. Valuable quantitative structure-activity relationships (QSARs) were also obtained in the titanocene class by using the same $\log P$ as the main parameter for the in vitro cytotoxic activity against HeLa, K562, and Fem-x cell lines.

Conclusions: According to our theoretical study, the titanocene/cyclodextrin inclusion compounds can be obtained (high interaction energy; the encapsulation is energetically favourable). Further, the most hydrophobic compounds are better encapsulated in $\beta$ - and $\gamma$-cyclodextrin molecules and are more stable (from energetically point of view) in comparison with a-cyclodextrin case. This study suggests that the titanocene / $\beta$ - and $\gamma$-cyclodextrin complexes (or synthetically modified cyclodextrins with higher water solubility) could be experimentally synthesized and could have enhanced cytotoxic activity and even lower toxicity.
\end{abstract}

Keywords: Metallocenes, Titanocenes, Cyclodextrins, Supramolecular systems, Molecular modelling, QSAR

\section{Background}

Cancer is a generic name comprises a great number of medical affections, having various locations and symptoms [1-5]. Even this disease is studied more than fifty years, the cause and action mechanisms are not completely elucidated $[3,6,7]$. Chemotherapy is widely used in order to cure this

\footnotetext{
*Correspondence: daniel.hadaruga@chim.upt.ro

${ }^{2}$ Department of Applied Chemistry and Organic-Natural Compounds Engineering, "Politehnica" University of Timişoara, Faculty of Industrial Chemistry and Environmental Engineering, Carol Telbisz 6, Timişoara 300001, Romania

Full list of author information is available at the end of the article
}

disease, by using various cytostatic or cytotoxic compounds: alkylating agents, antimetabolites, hormones, immunostimulating agents, antibiotics, alkaloids, all of them with higher toxicity $[1,8]$.

Organometallic compounds is an important class used in chemotherapy and the main groups studied are metallocenes (compounds which contains two cyclopentadienyl anions bound to a metal centre in the oxidation state II), ruthenium-, osmium-, iridium half-sandwich complexes, rhenium organometallics, metal $N$-heterocyclic carbene complexes, metal carbonyl complexes, or miscellaneous organometallic compounds [9]. The actual trend in cancer
() Chemistry Central 
treatment is to replace some of the more toxic drugs such as cisplatin with less toxic compounds. Organometallic compounds are widely studied from cytotoxic point of view. Ferrocene was one of the first organometallic compounds from the first group evaluated for its antiproliferative properties $[9,10]$. Ferrocene derivatives were obtained as antimalarial or cytostatic drugs and drug candidates [9]. Recently, similar metallocenes were synthesized and analyzed by biological activity point of view: ruthenocenes, cobaltoceniums, titanocenes, zirconocenes, vanadocenes, niobocenes, molibdocenes etc. [9-23]. The titanocene compounds are promising such drugs, but the hydrolytic instability and slightly water solubility conduct to a lower cytotoxic activity (approximately ten fold lower than cisplatin). Further, in the titanocene series cytotoxic activity against HeLa, K562, and Fem-x cell lines increases with the overall hydrophobicity of compounds $[16,17,22]$. On the other hand, increasing the hydrophobicity of titanocenes conducts to a more lower water solubility and reducing the transport capacity in aqueous layers (even the transport capacity through lipid layers are increased) [16,17]. Despite of the resemblance of titanocene dichloride derivatives with cisplatin, seems that the mode of action as anti-cancerigene is different: binding to DNA and apoptosis of the cancer cell for the cisplatin and binding to DNA phosphate group, with additional interaction stabilizing the binding to DNA, for titanocenes. Two main problems of the titanocene dihalides are the poor hydrosolubility and the hydrolytic instability [22].

These problems could be resolved in two ways: synthetically modifying the titanocene structure (laborious, other physico-chemical and biological analyses needed) or finding new formulations with enhanced properties [11,13,15,19,24-27]. Natural or chemically modified cyclodextrins (cyclic oligosaccharides with hydrophobic inner cavities and hydrosolubilizing outer groups) are widely used for protection, enhancing water solubility, and controlled release properties of bioactive compounds [28-34]. The aqueous solubility of metallocenes (i.e. titanocenes) with cytostatic or cytotoxic activities could be enhanced by molecular encapsulation in cyclodextrins, as well as the hydrolytic instability of these compounds could be reduced (by reducing the access of water molecules to the metallocene halide reaction centre) $[13,19,25,27]$.

This study presents a theoretical approach on the molecular encapsulation of a series of titanocenes with cytostatic activity in $\alpha-, \beta-$, and $\gamma$-cyclodextrin, in order to obtain supramolecular systems with enhanced stability and bioavailability. Further, a quantitative structurebiological activity relationships (QSAR) studies were performed in order to evaluate the main parameters which influencing the in vitro cytostatic activity.

\section{Results and discussion}

Quantitative structure-activity relationships (QSARs)

Molecular modelling and conformational analysis of titanocenes were performed by using the default parameters of $\mathrm{MM}+$ functionality from the HyperChem 5.11 package [35]. This method is appropriate especially for organic molecules, but in our organometallic series the "inner" metal did not have a major influence on the overall geometry of compounds. Titanocenes with cytotoxic activity indicate a reduced number of stable conformations, especially for structures with a lower flexible bonds (codes 01TC, 02TC, 08TC to 10TC); structures having dimethylvinyl-silyl-ethyl or trivinyl-silyl-ethyl moieties at the $\mathrm{Si}$, or pyridinium-methyl moieties at the cyclopentadienyl rings have a higher number of stable conformers; the most stable conformations are partially superimposed, especially at the titanocene skeleton. The most stable conformations have all flexible substituents $(Y, R$, and $R$ ' from the general structure, Table 1 and Scheme 1) oriented close to a pseudoplan formed by $\mathrm{Ti}$ and the gravity centres of the two cyclopentadiene rings (Figure 1) [see Additional file 1].

In order to evaluate the importance of titanocene structure/conformation to the overall cytotoxic activity, the most important steric, electronic, and hydrophobic descriptors were evaluated by using QSAR Properties functionality. Molecular van der Waals surface and volume, refractivity, and polarizability for titanocenes in minimum energy conformations were evaluated from sterical descriptor class (Table 2), but some intercorrelation exists, especially in the case of $S^{\nu d W}-V^{\nu d W}$ and $R f-P o l$ pairs (intercorrelation coefficient of 0.87 and 1.0, respectively, Table 3). This intercorrelation is poor for $S^{\nu d W} / V^{v d W}$ and $\mathrm{Rf} / \mathrm{Pol}$. Hydration energy has no correlation with descriptors from the other classes, but the transport parameter, $\log P$, correlates with $R f$ and $\mathrm{Pol}$ parameters with higher intercorrelation coefficients (inverse correlation of -0.85 and -0.87 , respectively, Table 3 ).

Taking into account these intercorrelations, only $\log P$, $R f$, and $P o l$ reveals statistically significant quantitative structure - cytotoxic activity relationships (QSARs) [36,37], which could drive molecular changes in this titanocene class in order to obtain new compounds with higher biological activity. In the case of HeLa cell line, in vitro cytotoxic activity of titanocenes correlates with the $\log P$ parameter (Eq. 1), having a correlation coefficient of 0.80 , which is higher than in the other cases; the correlation coefficient for the case of K562 is little bit lower (Eq. 2), but statistically significant, as well as in the case of Fem-x cell line (Eq. 3). A significant correlation was also obtained if the polarizability, Pol, was used as independent parameter (Eq. 4); for example, an inverse correlation exists between cytotoxic activity against $\mathrm{K} 562$ cells (expressed as $\mathrm{p} I C_{50}$ ) and polarizability $(r=0.80)$, but this parameter is intercorrelated with the 
Table 1 Titanocene structures (see Scheme 1) and in vitro cytotoxic activities ${ }^{(a)}$

\begin{tabular}{|c|c|c|c|c|c|}
\hline No & Code & Structure & $\mathrm{p} A_{1}$ & $\mathrm{p} A_{2}$ & $\mathrm{p} A_{3}$ \\
\hline 1 & $01 \mathrm{TC}$ & $\mathrm{M}: \mathrm{Si} ; \mathrm{X}: \mathrm{CH}_{3} ; \mathrm{Y}: \mathrm{CH}=\mathrm{CH}_{2} ; \mathrm{R}:$ all $\mathrm{H} ; \mathrm{R}^{\prime}$ : all $\mathrm{CH}_{3}$ & 4.10 & 4.20 & 3.87 \\
\hline 2 & 02TC & $\mathrm{M}: \mathrm{Si} ; \mathrm{X}: \mathrm{CH}_{3} ; \mathrm{Y}: \mathrm{H} ; \mathrm{R}$ : all $\mathrm{CH}_{3} ; \mathrm{R}^{\prime}$ : all $\mathrm{CH}_{3}$ & 3.96 & 4.23 & 3.93 \\
\hline 3 & 03TC & M: Si; X: $\mathrm{CH}_{3} ; \mathrm{Y}:\left(\mathrm{CH}_{2}\right)_{2} \mathrm{Si}\left(\mathrm{CH}_{3}\right)_{2}\left(\mathrm{CH}=\mathrm{CH}_{2}\right) ; \mathrm{R}$ : all $\mathrm{H}_{;} \mathrm{R}^{\prime}$ : all $\mathrm{CH}_{3}$ & 3.72 & 3.81 & 3.70 \\
\hline 4 & 08TC & $\mathrm{M}: \mathrm{Si} ; \mathrm{X}: \mathrm{CH}_{3} ; \mathrm{Y}: \mathrm{CH}_{3} ; \mathrm{R}$ : all $\mathrm{H}_{\text {; }} \mathrm{R}^{\prime}$ all $\mathrm{CH}_{3}$ & 3.87 & 4.18 & 4.02 \\
\hline 5 & 09TC & $\mathrm{M}: \mathrm{Ge} ; \mathrm{X}: \mathrm{CH}_{3} ; \mathrm{Y}: \mathrm{CH}_{3} ; \mathrm{R}:$ all $\mathrm{H} ; \mathrm{R}^{\prime}$ : all $\mathrm{CH}_{3}$ & 3.81 & 4.14 & 3.97 \\
\hline 6 & 10TC & $\mathrm{M}: \mathrm{Si} ; \mathrm{X}: \mathrm{CH}_{3} ; \mathrm{Y}: \mathrm{H} ; \mathrm{R}$ : all $\mathrm{CH}_{3} ; \mathrm{R}^{\prime}$ : all $\mathrm{CH}_{3}$ & 3.96 & 4.23 & 3.94 \\
\hline 7 & $11 \mathrm{TC}$ & $\mathrm{M}: \mathrm{Si} ; \mathrm{X}: \mathrm{CH}_{3} ; \mathrm{Y}: \mathrm{CH}_{3} ; \mathrm{R}: 3-\mathrm{CH}_{3}, 2,4,5-\mathrm{H}_{;}$R': all $\mathrm{CH}_{3}$ & 3.93 & 4.06 & 4.00 \\
\hline 8 & $18 \mathrm{TC}$ & $\mathrm{M}: \mathrm{Si} ; \mathrm{X}: \mathrm{CH}_{3} ; \mathrm{Y}:\left(\mathrm{CH}_{2}\right)_{2} \mathrm{Si}\left(\mathrm{CH}=\mathrm{CH}_{2}\right)_{3} ; \mathrm{R}$ : all $\mathrm{H} ; \mathrm{R}^{\prime}$ : all $\mathrm{CH}_{3}$ & 3.70 & 3.70 & \\
\hline 9 & 23TC & $\mathrm{M}, \mathrm{X}, \mathrm{Y}$ : none; $\mathrm{R}: 3-\mathrm{CH}_{2}$ (3-pyridinium); $\mathrm{R}^{\prime}$ : all $\mathrm{H}$ & 3.94 & & \\
\hline 10 & $24 \mathrm{TC}$ & $\mathrm{M}, \mathrm{X}, \mathrm{Y}:$ none; $\mathrm{R}: 3-\mathrm{CH}_{2}$ (3-pyridinium); $\mathrm{R}^{\prime}$ : 3- $\mathrm{CH}_{2}$ (3-pyridinium) & 4.25 & & \\
\hline 11 & $26 \mathrm{TC}$ & $\mathrm{M}, \mathrm{X}, \mathrm{Y}$ : none; $\mathrm{R}: 3-\mathrm{CH}_{2}$ (4-pyridinium); $\mathrm{R}^{\prime}$ : 3- $\mathrm{CH}_{2}$ (4-pyridinium); & 4.97 & & \\
\hline
\end{tabular}

(a) cytotoxic activity was expressed as the logarithm of the inverse inhibitory concentration $50 \%, \mathrm{p} / C_{50}=\log \left(1 / / C_{50}\right) ; \mathrm{p} A_{1}, \mathrm{p} A_{2}, \mathrm{p} A_{3}$ were used for in vitro cytotoxic activity against HeLa, K562, and Fem-x cell lines, respectively.

hydrophobic one. As a result, if the polarizability is lower, the hydrophobicity is increased and the transport, the interaction of titanocene with the hydrophobic cell membrane is favoured, and further the cytotoxic activity is increased. The predictive accuracy was evaluated by cross-validation method (leave-half-out method), all models having cross-validation correlation coefficients $q_{c v}^{2}>0.75$ [see Additional file 1]. The predicted $\mathrm{p} A$ activities, calculated with equations Eq. 1 to Eq. 4, as well as the differences between experimental and predicted activities, are presented in Table 4 [see Additional file 1].

QSAR results (Table 4 and Eqs. 1-4) indicate very good predictions of cytotoxic activity against HeLa and Fem-x cell lines, especially in the case of compounds 01TC-11TC $(|\Delta \mathrm{p} A|<0.11$, except compound 09TC for HeLa cytotoxic activity; this compound contains $\mathrm{Ge}$ as the second metal atom, in comparison with the other titanocene compounds, which contain only $\mathrm{Si}$ instead). Higher differences were observed in the case of pyridinium-methyl derivatives which have no $\mathrm{Si}$ as the second metal atom; the

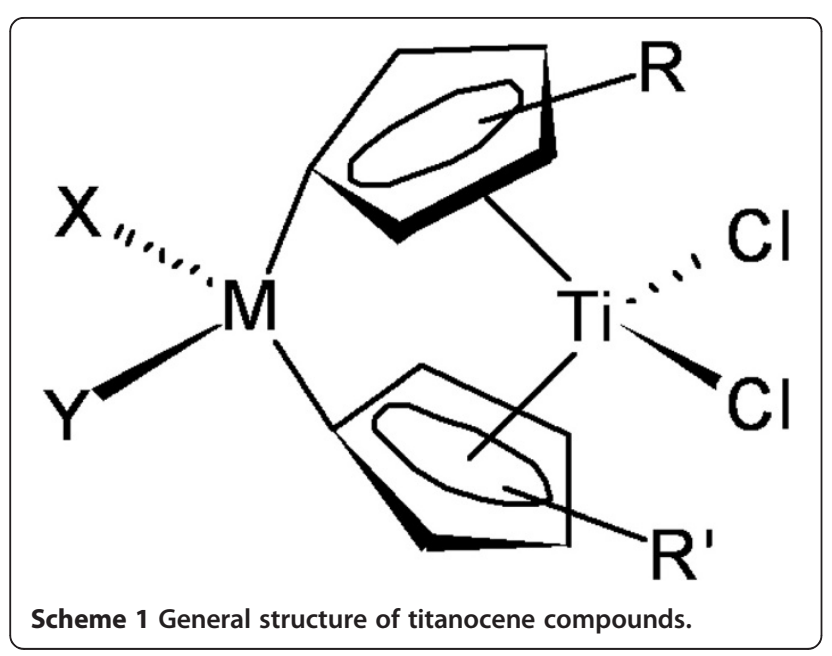

presence of $\mathrm{Si}$ atom in the structure stabilizes the overall titanocene structure (compounds 23TC, 24TC, and 26TC). Good results were obtained for prediction of the cytotoxic activity against $\mathrm{K} 562$ cell lines for models obtained with $\log P$ and $R f$ as structural parameters (Eqs. 2 and 4). The difference between experimental and predicted activity was lower than 0.2 in almost all titanocene cases (except compound 18TC, having trivinyl-silyl moiety and the highest $R f$ value) (Table 4). However, a correlation between predicted activities against K562 cell lines obtained with Eqs. 2 and 4 exists $(r=0.67)$; this result is sustained by the $\log P-R f$ intercorrelation coefficient which are involved in Eqs. 2 and 4 (Table 3).

$$
\begin{aligned}
& p A_{1 i}=3.40( \pm 0.17)+0.69( \pm 0.17) \cdot \log P_{i} \\
& n=11 ; r=0.80 ; F=16 ; q_{c v}^{2}=0.75 \\
& p A_{2 i}=3.54( \pm 0.23)+0.69( \pm 0.30) \cdot \log P_{i} \\
& n=8 ; r=0.70 ; F=5.5 ; q_{c v}^{2}=0.88 \\
& p A_{3 i}=3.63( \pm 0.12)+0.39( \pm 0.16) \cdot \log P_{i} \\
& n=7 ; r=0.74 ; F=5.9 ; q_{c v}^{2}=0.80 \\
& p A_{2 i}=5.27( \pm 0.37)-0.014( \pm 0.004) \cdot R f_{i} \\
& n=11 ; r=0.80 ; F=10.5 ; q_{c v}^{2}=0.75
\end{aligned}
$$

\section{Geometry optimization of titanocene / cyclodextrin supramolecular systems}

It is known that the cytotoxic activity of titanocene dichloride is different from cisplatin action (the last being more toxic, but with higher cytotoxic activity): titanocenes conduct to adduct with DNA and prevent the replication and/or transcription, resulting in cell death [22]. Thus, the transport of titanocene to the DNA is very important, but the lower water solubility 

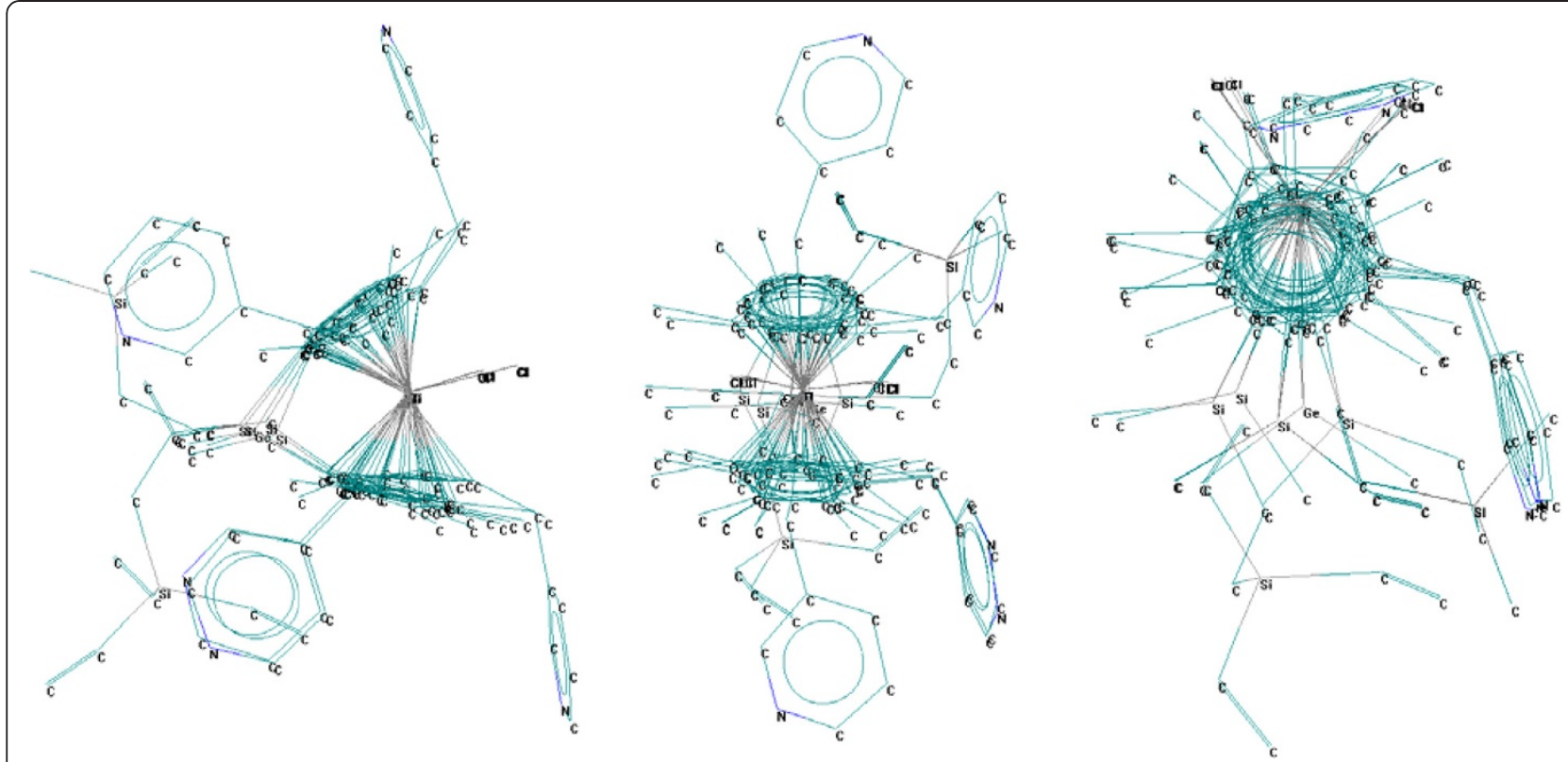

Figure 1 Superimposed minimum energy conformations of titanocene structures (OX, OY, and $\mathrm{OZ}$ view).

and instability (hydrolysis of chloride ligands) reduces the access to the target - biomacromolecules; on the other hand, if the hydrophobicity is increased (the QSAR study indicates a higher in vitro biological activity for more hydrophobic titanocenes), the titanocene transfer in aqueous layer is decreased (especially in the case of the in vivo experiments). Thus, the increase of the hydrophobicity in order to enhance the in vitro cytotoxic activity conducts to a less water solubility and a harder transport of the titanocenes to the target. The water solubility of hydrophobic molecules could be realized by molecular encapsulation in matrices such as cyclodextrins. Among the increasing of water solubility, the advantage of this procedure is to protect of easier hydrolysable titanocenes against degradation and controlled release to the target (i.e. DNA); further, the higher hydrophobicity of modified titanocenes conduct to a better interaction with the hydrophobic inner cavity of cyclodextrins.

Fully geometry optimization of titanocene / cyclodextrin supramolecular systems or docking of organometallic compounds in cyclodextrins [38,39] could provide information on the stability of complexes and suggest chemical modifications for new titanocenes with higher cytotoxic activity. In our theoretical experiments of fully geometry optimization of titanocene / cyclodextrin supramolecular systems in vacuum (the default HyperChem molecular mechanics MM+ force field was used), only the interaction of the hydrophobic moiety of titanocene with the inner cavity of cyclodextrins from the secondary face was efficient (higher stability of the complex). The main interactions which stabilize the titanocene / cyclodextrin complex in vacuum were bond stretching energy, the angle bending energy, the torsional energy, and the energy arising from van der Waals interactions of non-bonded pairs of atoms. Due to the fact that all titanocene compounds from the studied series are chemically similar molecules, we have an internal consistency from the force field point of view [15,40-49].

In the case of $\alpha$-cyclodextrin, the interaction of titanocenes with the secondary face is poor, even with structures having thin hydrophobic chains (e.g. 03TC, 18TC, 23TC, 24TC, and 26TC; Figure 2) [see Additional file 1]; the worst interaction was observed for the case of titanocene oriented to the primary face of $\alpha$-cyclodextrin or with the titanocene moiety in the front of both cyclodextrin rings. Theoretical interaction energy between titanocenes and $\alpha$-cyclodextrin was in the range of $11.9 \mathrm{kcal} /$ mole to $19.7 \mathrm{kcal} / \mathrm{mole}$ (Table 5). The best interactions of titanocenes with $\alpha$-cyclodextrin were obtained in the case of structures having compounds monosubstituted at the $\mathrm{Si}\left(02 \mathrm{TC}\right.$ and $10 \mathrm{TC}, E_{\text {int. }} 19.7 \mathrm{kcal} / \mathrm{mole}$ and 17.0 $\mathrm{kcal} / \mathrm{mole}$, respectively) or having flexible chain connected to this atom (03TC and $18 \mathrm{TC}, E_{\text {int. }} 18.0 \mathrm{kcal} /$ mole and $17.0 \mathrm{kcal} / \mathrm{mole}$, respectively). Lower interaction energies between titanocenes and $\alpha$-cyclodextrin were obtained for compounds di-substituted at the $\mathrm{Si}$ atom with short chain moieties (methyl or vinyl) and for those substituted at the cyclopentadienyl rings with pyridinium-methyl moieties (Table 5). These low interaction energies are especially due to the geometric compatibilities, which are close to the limits and the interactions with the hydrophobic inner cavity of $\alpha$ - 
Table 2 Values of the structural descriptors ${ }^{(a)}$ for minimum energy conformations of titanocenes

\begin{tabular}{llllclll}
\hline No & Code & $\begin{array}{c}S^{\text {vdW }} \\
\left(\AA^{2}\right)\end{array}$ & $\begin{array}{c}\boldsymbol{V}^{\text {vdW }} \\
\left(\AA^{3}\right)\end{array}$ & $\begin{array}{c}E_{\text {hydr }} \\
(\mathrm{kcal} / \mathrm{mole})\end{array}$ & $\log P$ & $\begin{array}{c}\boldsymbol{R} \boldsymbol{R} \\
\left(\AA^{3}\right)\end{array}$ & $\begin{array}{c}P o l \\
\left(\AA^{3}\right)\end{array}$ \\
\hline 1 & 01TC & 340 & 317 & 1.68 & 0.86 & 77.7 & 33.4 \\
2 & 02TC & 359 & 351 & 3.57 & 0.80 & 87.7 & 37.3 \\
3 & 03TC & 446 & 414 & 3.10 & 0.36 & 98.5 & 43.1 \\
4 & 08TC & 327 & 302 & 2.97 & 0.73 & 74.0 & 31.8 \\
5 & 09TC & 310 & 297 & 2.72 & 1.06 & 75.5 & 32.5 \\
6 & 10TC & 506 & 958 & 3.55 & 0.80 & 87.7 & 37.3 \\
7 & 11TC & 492 & 897 & 3.32 & 0.81 & 78.6 & 33.6 \\
8 & 18TC & 470 & 438 & 0.70 & 0.62 & 106.0 & 46.3 \\
9 & 23TC & 305 & 273 & -3.02 & 0.51 & 74.6 & 30.4 \\
10 & 24TC & 401 & 361 & -7.32 & 1.63 & 103.0 & 41.7 \\
11 & 26TC & 401 & 361 & -7.85 & 1.63 & 103.0 & 41.7 \\
\hline
\end{tabular}

(a) van der Waals molecular surface $\left(S^{v d W}, \AA^{2}\right)$, van der Waals molecular volume $\left(V^{v d W}, \AA^{3}\right)$, hydration energy $\left(E_{\text {hydr }}, \mathrm{kcal} / \mathrm{mole}\right)$, logarithm of the octanol/water partition coefficient $(\log P)$, refractivity $\left(R f, \AA^{3}\right)$, and polarizability $\left(P o l, \AA^{3}\right)$.

cyclodextrin are reduced. This is the reason that the hydrophobicity (expressed as $\log P$ ) is not important $(r<0.5)$ in relation with the titanocene / $\alpha$-cyclodextrin interaction energy, while the hydration energy $\left(E_{h y d r}\right.$. $)$ weak correlates with this interaction energy (Eq. 5).

$$
\begin{aligned}
E_{\text {int }, a C D, i}= & 15.54( \pm 0.57) \\
& +0.356( \pm 0.137) \cdot E_{\text {hydr }, a C D, i}
\end{aligned}
$$

$n=11 ; r=0.656 ; F=6.8$

The superior homologues, $\beta$ - and $\gamma$-cyclodextrins, are more proper for molecular encapsulation of the studied titanocenes (Figures 3 and 4). In all $\beta$ - and $\gamma$ cyclodextrin complexes the mono- or disubstituted silyl moiety, the bulky moiety (dimethyl-vinyl-silyl or trivinylsilyl substituents) from the edge of the corresponding substituent, or the pyridinium-methyl substituent from the cyclopentadienyl ring are almost completely encapsulated in the cyclodextrin cavities [see Additional file 1]. In these cases the hydrophobicity of titanocenes (quantified by the logarithm of the 1-octanol/water partition coefficient) was important for the molecular encapsulation process and the interaction energy correlates

Table 3 Intercorrelational matrix for titanocene structural descriptors

\begin{tabular}{lcccccc}
\hline & $\boldsymbol{S}^{\text {vdW }}$ & $\boldsymbol{V}^{\text {vdW }}$ & $E_{\text {hydr }}$ & $\log P$ & $\boldsymbol{R f}$ & $\boldsymbol{P o l}$ \\
\hline $\boldsymbol{S}^{\text {vdW }}$ & 1.00 & $\mathbf{0 . 9 1}$ & 0.54 & -0.40 & 0.52 & 0.49 \\
$\boldsymbol{V}^{\text {vdW }}$ & & 1.00 & 0.52 & -0.02 & 0.17 & 0.13 \\
$E_{\text {hydr }}$ & & & 1.00 & -0.23 & 0.43 & 0.38 \\
$\log P$ & & & & 1.00 & $-\mathbf{0 . 7 7}$ & $-\mathbf{0 . 8 0}$ \\
$\boldsymbol{R f}$ & & & & & 1.00 & $\mathbf{1 . 0 0}$ \\
Pol & & & & & & 1.00 \\
\hline
\end{tabular}

with $\log P$ in a statistically significant way (Eq. 6 and Eq. 7). Thus, better interactions were obtained with the titanocenes having pyridinium-methyl substituents on the cyclopentadienyl rings (codes 24TC and 26TC), the interaction energy being $23.7-24.3 \mathrm{kcal} / \mathrm{mole}$ and $27.3-28.1 \mathrm{kcal} / \mathrm{mole}$ for $\beta$ - and $\gamma$-cyclodextrin, respectively (Table 5). Higher interaction energies were obtained also for titanocenes having monosubstituted silyl moieties, 02TC and 10TC, especially in the case of $\gamma$-cyclodextrin complexes $(28.4 \mathrm{kcal} / \mathrm{mole}$ and $28.6 \mathrm{kcal} /$ mole, respectively; Table 5). Furthermore, a statistically significant correlation between titanocene $/ \beta$ - and $\gamma$ cyclodextrin interaction energies was observed $(r=0.82)$ [see Additional file 1].

$$
\begin{array}{rl}
E_{\text {int. }, b C D, i}= & 16.24( \pm 1.64) \\
& +4.459( \pm 1.687) \cdot \log P_{b C D, i} \\
n=11 ; r=0 & 0.661 ; F=7.0 \\
E_{\text {int. } g C D, i}= & 21.46( \pm 1.99) \\
& +4.347( \pm 2.047) \cdot \log P_{g C D, i}
\end{array}
$$

$n=11 ; r=0.578 ; F=4.1$

The stability of the titanocene / cyclodextrin supramolecular system is observed from Figure 5 for $\beta$ - and $\gamma$ cyclodextrin cases: the better stability is obtained in the case of $\gamma$-cyclodextrin, followed by $\beta$-cyclodextrin case, and finally for $\alpha$-cyclodextrin complex after more than double number of iterations. This variation of the energy interaction reveals the possibility of forming the titanocene/cyclodextrin complexes and the stability of these supramolecular systems [see Additional files 1 and 2].

\section{Conclusions}

In our study the importance of the hydrophobic parameter $(\log P$ - the logarithm of the octanol/water partition coefficient) in both of in vitro cytotoxic activity against HeLa, K562, and Fem-x cell lines, as well as in the cyclodextrin nanoencapsulation of the titanocene compounds were demonstrated.

Our theoretical studies demonstrates that the molecular encapsulation of titanocenes in natural cyclodextrins could resolves some of cytotoxic titanocene disadvantages: a more hydrophobic titanocene, which have higher cytotoxic activity (the in vitro cytotoxic activity against HeLa, K562, and Fem-x cell lines is increased with the $\log P$ of the titanocene compound; $r>0.7$ ), is better encapsulated in cyclodextrins and could be transported through the aqueous layers (cyclodextrin inclusion compounds are water soluble) and protected against hydrolysis. Our theoretical study on the titanocene / cyclodextrin complexes indicate that the hydrophobic biologically active compounds (with higher cytotoxic activity) are better encapsulated in $\beta$ - and $\gamma$-cyclodextrin; the highest 
Table 4 QSAR results for cytotoxic activity of titanocenes against HeLa, K562, and Fem-x cell lines (experimental activities $-A$ and $\mathrm{p} A$, predicted activities $-\mathrm{p} A_{(\text {pred.), }}$ and the differences between experimental and predicted activities, $\Delta \mathrm{pA})$

\begin{tabular}{|c|c|c|c|c|c|c|c|c|c|c|c|c|c|c|c|}
\hline $\begin{array}{l}\text { No } \\
\text { (a) }\end{array}$ & Code & $\frac{A_{1}}{\left(I C_{50 r H e L a r} \mu \mathrm{M}\right)^{(b)}}$ & $\frac{A_{2}}{\left(I C_{50, K 562}, \mu \mathrm{M}\right)^{(b)}}$ & $\frac{A_{3}}{\left(I C_{50, \text { Fem-x }} \mu \mathrm{M}\right)^{(\mathrm{b})}}$ & $\mathrm{p} A_{(b)}$ & $\mathrm{p}_{(\mathrm{b})}$ & $\mathrm{p}_{(\mathrm{b})} A_{3}$ & $\begin{array}{l}\mathrm{p} A_{1} \\
\text { (pred.) } \\
\text { (b) }\end{array}$ & $\underset{\substack{\text { (pred.) } \\
(\text { b) }}}{\mathrm{p} A_{2}}$ & $\begin{array}{l}\mathrm{p} A_{3} \\
\text { (pred.) } \\
\text { (b) }\end{array}$ & $\begin{array}{c}\mathrm{p} A_{2,} \\
R f \\
\text { (pred.) } \\
(\text { b) }\end{array}$ & $\Delta \mathrm{p}_{(\mathrm{b})} A_{1}$ & $\Delta \mathrm{p}_{(\mathrm{b})} A_{2}$ & $\Delta \mathrm{p}_{(\mathrm{b})} A_{3}$ & $\underset{R f}{\Delta \mathrm{p} A_{2}}$ \\
\hline 1 & 01TC & $79.2 \pm 6.9$ & $63.7 \pm 9.5$ & $134.3 \pm 18.1$ & 4.10 & 4.20 & 3.87 & 3.99 & 4.13 & 3.97 & 4.18 & 0.11 & 0.07 & -0.10 & 0.02 \\
\hline 2 & 02TC & $108.6 \pm 8.6$ & $59.4 \pm 8$ & $116.3 \pm 8.7$ & 3.96 & 4.23 & 3.93 & 3.95 & 4.09 & 3.94 & 4.04 & 0.01 & 0.14 & -0.01 & 0.19 \\
\hline 3 & 03TC & $189 \pm 13.1$ & $155.2 \pm 8.7$ & 200 & 3.72 & 3.81 & 3.70 & 3.65 & 3.79 & 3.77 & 3.89 & 0.07 & 0.02 & -0.07 & -0.08 \\
\hline 4 & 08TC & $135 \pm 6$ & $66 \pm 6$ & $96 \pm 4$ & 3.87 & 4.18 & 4.02 & 3.90 & 4.04 & 3.92 & 4.23 & -0.03 & 0.14 & 0.11 & -0.05 \\
\hline 5 & 09TC & $154 \pm 4$ & $73 \pm 1$ & $106 \pm 5$ & 3.81 & 4.14 & 3.97 & 4.13 & 4.27 & 4.04 & 4.21 & -0.32 & -0.13 & -0.07 & -0.07 \\
\hline 6 & 10TC & $109 \pm 9$ & $59 \pm 8$ & $116 \pm 9$ & 3.96 & 4.23 & 3.94 & 3.95 & 4.09 & 3.94 & 4.04 & 0.01 & 0.14 & -0.00 & 0.19 \\
\hline 7 & $11 T C$ & $117 \pm 3$ & $88 \pm 4$ & $101 \pm 9$ & 3.93 & 4.06 & 4.00 & 3.96 & 4.10 & 3.95 & 4.17 & -0.03 & -0.04 & 0.05 & -0.11 \\
\hline 8 & $18 \mathrm{TC}$ & 200 & 200 & & 3.70 & 3.70 & & 3.83 & 3.97 & & 3.79 & -0.13 & -0.27 & & -0.09 \\
\hline 9 & $23 \mathrm{TC}$ & $114.2 \pm 57$ & & & 3.94 & & & 3.75 & & & & 0.19 & & & \\
\hline 10 & $24 \mathrm{TC}$ & $55.9 \pm 16.2$ & & & 4.25 & & & 4.53 & & & & -0.28 & & & \\
\hline 11 & $26 \mathrm{TC}$ & $10.8 \pm 0.6$ & & & 4.97 & & & 4.53 & & & & 0.45 & & & \\
\hline
\end{tabular}

(a) Compounds No 1-3 are selected from reference [16], compounds No 4-8 from [17], and compounds No 9-11 from [22].

(b) $A\left(I C_{50}, \mu \mathrm{M}\right)$ - the in vitro cytotoxic activity $( \pm \mathrm{SD})$ of titanocenes selected from references $[16,17,22] ; \mathrm{p} A$ - the logarithm of the inverse inhibitory concentration $50 \%, \mathrm{p} / C_{50}=\log \left(1 / / C_{50}\right) ; \mathrm{p} A_{\text {pred. }}-$ the predicted cytotoxic activity (as the logarithm of the predicted inverse inhibitory concentration $50 \%$, $\mathrm{p} A_{\text {pred. }}=\mathrm{p} / C_{50,}$ pred. $=\log$ $\left(1 / / C_{50, p r e d}\right) ; \Delta \mathrm{p} A$ - the difference between experimental and predicted activities (as the logarithm of the inverse inhibitory concentration $\left.50 \%\right), \triangle \mathrm{p} A=\mathrm{p} A-\mathrm{p} A_{\text {pred. }}$

titanocene / $\beta$ - and $\gamma$-cyclodextrin complex interaction energies of $\sim 24 \mathrm{kcal} /$ mole and $\sim 28 \mathrm{kcal} /$ mole was obtained in vacuum for bis(pyridinium-methyl)-silyl derivatives, respectively. This study indicate that the titanocene compound can be controlled released to the target from the cyclodextrin complex; this complex allow to transfer the more hydrophobic titanocene through lipid layers, to increase the concentration of bioactive compound to the DNA phosphoester groups and further to form the titanocene-DNA adducts. Due to this process the inhibition of DNA transcription and/or replication appears (cytotoxicity).

According to our theoretical study, these titanocene/ cyclodextrin inclusion compounds can be obtained (the encapsulation process is energetically favourable for $\beta$ - and $\gamma$-cyclodextrin complexes). Further, the most hydrophobic compounds are better encapsulated in $\beta$ - and $\gamma$-cyclodextrin molecules and are more stable (from energetically point of view) in comparison with $\alpha$ cyclodextrin case. This study suggests that the titanocene $/ \beta$ - and $\gamma$-cyclodextrin complexes (or synthetically modified cyclodextrins with higher water solubility) could be experimentally synthesized and could have enhanced cytotoxic activity and even lower toxicity.

\section{Methods}

Titanocene structure selection and cytotoxic activity

Titanocenes with potential anticarcinogenic properties were recently synthesized by Gómez-Ruiz et al. [16,17] and Potter et al. [22] and have structural variability at the cyclopentadienyl moieties. All these new titanocene structures (eleven organometallic compounds) with cytotoxic activity against cervical carcinoma cell line
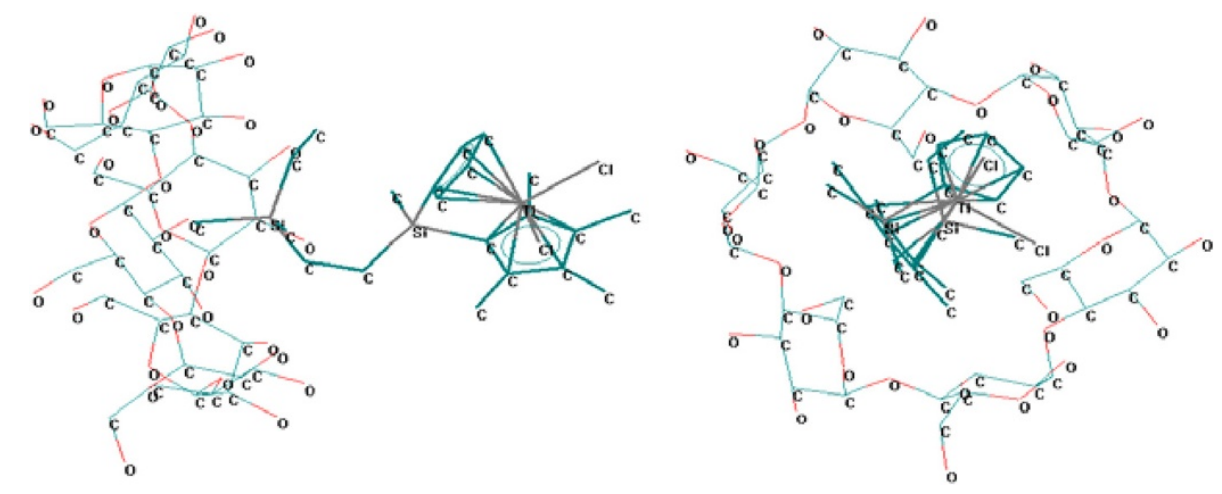

Figure 2 Titanocene (code 03TC) / a-cyclodextrin supramolecular system (theoretically modeled by MM+). 
Table 5 Energies (resulted from the $M M+$ molecular modeling and titanocene/cyclodextrin optimization experiments) for cyclodextrins $\left(E_{C D}, \alpha-, \beta-\right.$, and $\gamma$-cyclodextrin, codes aCD, bCD, and gCD), titanocenes $\left(E_{T C .}\right.$, codes $x T C$, where $x=01-$ $03,08-11,18,23,24$, and 26$)$, the sum of titanocene and cyclodextrin energies, with no interaction $\left(E_{T C .+C D}\right)$, the energies of the TC-CD complex $\left(E_{T C .-C D}\right.$ complex $)$, and the TC-CD interaction energies $\left(E_{\text {int. }}\right)$, determined as the difference between the TC+CD energy, with no interaction, and the energy of the TC-CD complex

\begin{tabular}{|c|c|c|c|c|c|c|}
\hline No & Code & $\begin{array}{c}E_{C D} \\
\text { (kcal/mole) }\end{array}$ & $\begin{array}{c}E_{T C} \\
\text { (kcal/mole) }\end{array}$ & $\begin{array}{c}E_{T C .+C D} \\
\text { (kcal/mole) }\end{array}$ & 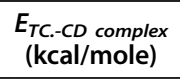 & $\begin{array}{c}E_{\text {int. }} \\
\text { (kcal/mole) }\end{array}$ \\
\hline 1 & 01TC_aCD & & 572.70 & 642.05 & 626.0 & 16.08 \\
\hline 2 & 02TC_aCD & & 601.41 & 670.76 & 651.1 & 19.67 \\
\hline 3 & 03TC_aCD & & 567.76 & 637.11 & 619.1 & 17.97 \\
\hline 4 & 08TC_aCD & & 571.92 & 641.27 & 624.8 & 16.43 \\
\hline 5 & 09TC_aCD & & 686.73 & 756.08 & 740.3 & 15.79 \\
\hline 6 & 10TC_aCD & 69.35 & 601.53 & 670.88 & 653.8 & 17.04 \\
\hline 7 & 11TC_aCD & & 575.11 & 644.46 & 631.6 & 12.88 \\
\hline 8 & 18TC_aCD & & 571.08 & 640.43 & 623.4 & 16.98 \\
\hline 9 & 23TC_aCD & & 557.15 & 626.50 & 613.3 & 13.19 \\
\hline 10 & 24TC_aCD & & 566.55 & 635.90 & 624.0 & 11.90 \\
\hline 11 & 26TC_aCD & & 566.44 & 635.79 & 621.5 & 14.28 \\
\hline 12 & 01TC_bCD & & 572.70 & 652.50 & 637.9 & 14.64 \\
\hline 13 & 02TC_bCD & & 601.41 & 681.21 & 660.1 & 21.11 \\
\hline 14 & 03TC_bCD & & 567.76 & 647.56 & 630.8 & 16.73 \\
\hline 15 & 08TC_bCD & & 571.92 & 651.72 & 632.2 & 19.51 \\
\hline 16 & 09TC_bCD & & 686.73 & 766.53 & 746.0 & 20.50 \\
\hline 17 & 10TC_bCD & 79.80 & 601.53 & 681.33 & 660.8 & 20.49 \\
\hline 18 & 11TC_bCD & & 575.11 & 654.91 & 634.9 & 19.97 \\
\hline 19 & 18TC_bCD & & 571.08 & 650.88 & 629.1 & 21.76 \\
\hline 20 & 23TC_bCD & & 557.15 & 636.95 & 617.3 & 19.68 \\
\hline 21 & 24TC_bCD & & 566.55 & 646.35 & 622.0 & 24.32 \\
\hline 22 & 26TC_bCD & & 566.44 & 646.24 & 622.6 & 23.65 \\
\hline 23 & 01TC_gCD & & 572.70 & 663.99 & 640.2 & 23.78 \\
\hline 24 & 02TC_gCD & & 601.41 & 692.70 & 664.3 & 28.36 \\
\hline 25 & 03TC_gCD & & 567.76 & 659.05 & 635.6 & 23.44 \\
\hline 26 & 08TC_gCD & & 571.92 & 663.21 & 637.1 & 26.09 \\
\hline 27 & 09TC_gCD & & 686.73 & 778.02 & 752.4 & 25.61 \\
\hline 28 & 10TC_gCD & 91.29 & 601.53 & 692.82 & 664.2 & 28.59 \\
\hline 29 & $11 \mathrm{TC} \_g C D$ & & 575.11 & 666.40 & 639.6 & 26.83 \\
\hline 30 & 18TC_gCD & & 571.08 & 662.37 & 640.9 & 21.43 \\
\hline 31 & 23TC_gCD & & 557.15 & 648.44 & 629.3 & 19.10 \\
\hline 32 & $24 T C \_g C D$ & & 566.55 & 657.84 & 629.7 & 28.12 \\
\hline 33 & 26TC_gCD & & 566.44 & 657.73 & 630.4 & 27.34 \\
\hline
\end{tabular}

HeLa, human myelogenous leukemia cell line K562, and human malignant carcinoma cell line Fem-x were considered in this theoretical study. Cytotoxic activity was expressed as the logarithm of the inverse inhibitory concentration 50\%, $\mathrm{p} I C_{50}=\log \left(1 / I C_{50}\right) ; \mathrm{p} A_{1}, \mathrm{p} A_{2}, \mathrm{p} A_{3}$ were used for cytotoxic activity against HeLa, K562, and Fem-x, respectively (Table 1).

\section{Molecular modelling}

Molecular modelling of titanocene molecules as well as $\alpha-, \beta-$, and $\gamma$-cyclodextrins was performed by using the molecular mechanics $\mathrm{MM}+$ functionality from the HyperChem 5.11. The MM+ molecular mechanics force field with a RMS of $0.005 \mathrm{kcal} /$ mole, a number of maximum cycles to limit the search directions of fifteen 

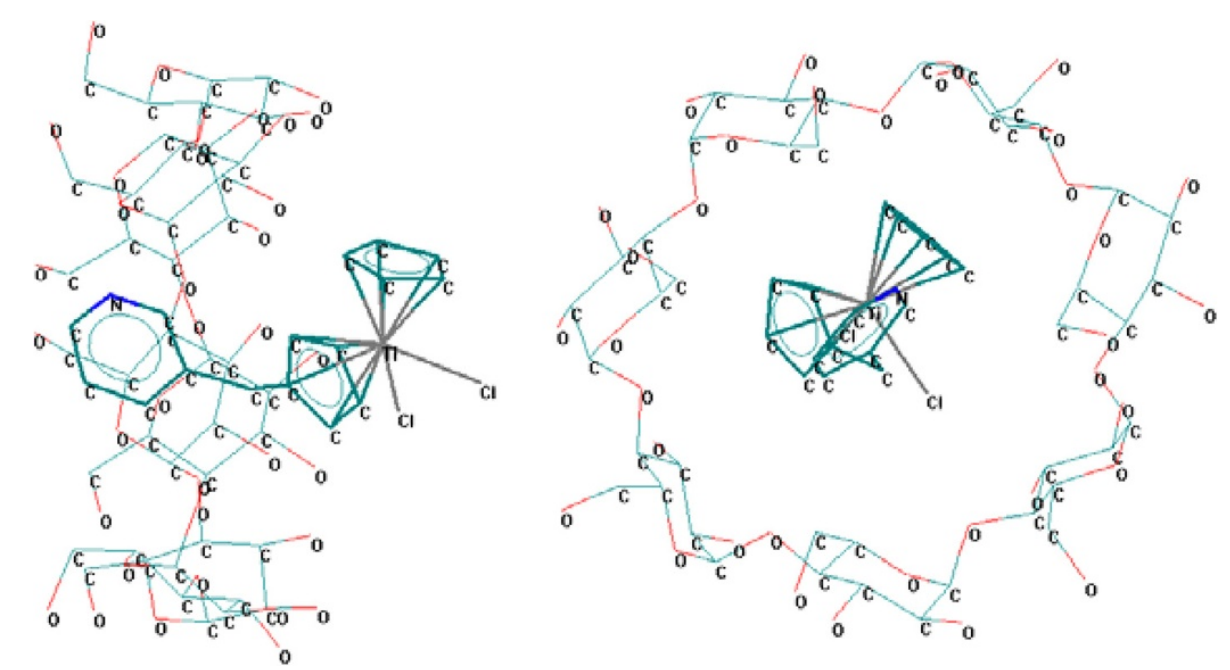

Figure 3 Titanocene (code 23TC) / $\beta$-cyclodextrin supramolecular system (theoretically modeled by MM+).

times the number of atoms, and a Polak-Ribiere algorithm (a gradient method using one-dimensional searches) were used in the molecular modelling process. Bond dipole was used to calculate all nonbonded electrostatic interactions. In the $\mathrm{MM}+$ calculations potential energy depends on bond lengths, bond angles, torsion angles, and nonbonded interactions (van der Waals forces, electrostatic interactions, and hydrogen bonds) [50,51].

\section{Conformational analysis}

In order to find the most stable conformation even for titanocenes or cyclodextrins, a conformational analysis by using Conformational Search functionality (HyperChem 5.11) was performed. In titanocene structures only some side chains have flexible bonds. On the other hand, the flexible bonds in cyclodextrins were only those corresponding to the hydroxymethyl from $\mathrm{C}^{5}$ position of glucopyranose unit; the flexible rings were all glucopyranose rings and the corresponding macrocyclic ring. The following conditions were set up for conformational search: variation of the flexible torsion angles $\pm 60^{\circ} \div \pm 180^{\circ}$, energy criterion for acceptance of the conformation $4 \mathrm{kcal} / \mathrm{mole}$ above minimum, all conformations with atomic distances lower than $0.5 \AA$, and differences between torsion angles lower than $15^{\circ}$ were not considered as well as conformations with energy differences lower than $0.05 \mathrm{kcal} / \mathrm{mole}$ (duplicates); the maximum number of optimization and iterative calculations was 1000 and maximum 20 conformations were retained. The hydrogen atoms were neglected.

\section{Geometry optimization of titanocene / cyclodextrin supramolecular systems}

The geometry optimization of titanocene (the most stable conformations) / cyclodextrin ( $\alpha$-, $\beta$-, and $\gamma$-cyclodextrin) complexes was realized by using the molecular mechanics interactions of the host-guest molecules in vacuum. The titanocene and cyclodextrin structures in minimal energy conformations were set up at distances of $\sim 8 \AA$ between the gravity centres of the host-guest molecules, and the titanocene structure was oriented with the hydrophobic side chain in front of the primary (A) or secondary (B) face of cyclodextrin (the principal axis corresponding to the biocompound or side chain moiety was perpendicular to the A or B plan of cyclodextrin). The complex was modeled in absence of water molecules by using the same MM+ functionality and the interaction was stopped when the RMS gradient was lower than $0.005 \mathrm{kcal} / \mathrm{mole}$. The titanocene-cyclodextrin interaction energy was evaluated as the difference between the overall energies of these two molecules and the energy of the complex.

\section{Structural parameters, correlations, and QSARs}

The main molecular descriptors of titanocenes were evaluated by using QSAR Properties functionality from the HyperChem 5.11 package. The following descriptors were calculated and were used as structural parameters for obtaining correlations with titanocene-cyclodextrin interaction energy or quantitative structure-activity relationships (QSARs): van der Waals molecular surface $\left(S^{\nu d W}, \AA^{2}\right.$; van der Waals surface area was carried out by an approximate developed by Still and co-workers $[52,53])$, van der Waals molecular volume $\left(V^{\nu d W}, \AA^{3}\right.$; the grid method described by Bodor et al. [54] was used for van der Waals volume calculation. The QSAR Properties functionality uses the atomic radii of Gavezotti [55] for this method), hydration energy ( $E_{h y d n}, \mathrm{kcal} / \mathrm{mole}$; the method of calculation is developed by Ooi et al. [56]. The calculation is based on exposed surface area, and employs the surface area as computed by the approximate method, 

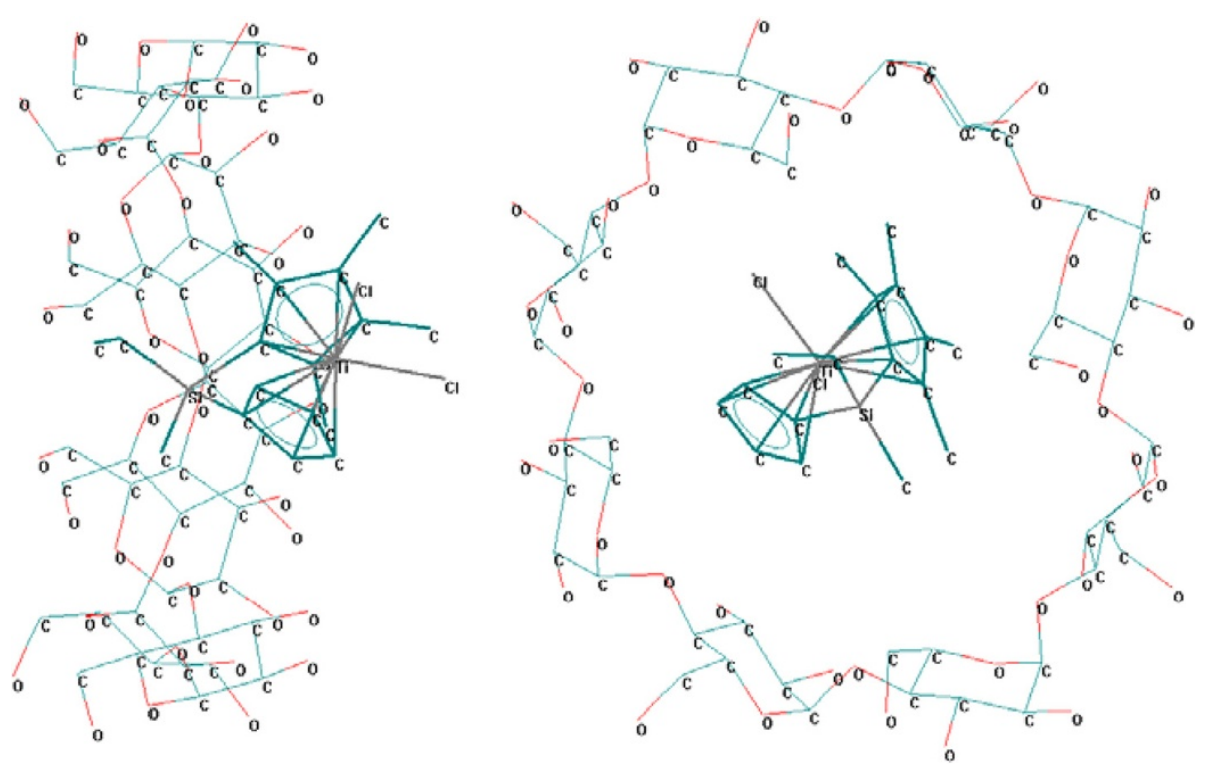

Figure 4 Titanocene (code 01TC) / $\mathrm{Y}$-cyclodextrin supramolecular system (theoretically modeled by MM+).

weighted by atom type), logarithm of the octanol/water partition coefficient $(\log P$; it was calculated by means of atomic contributions [57,58]. Metal atoms were excepted from calculation; this approximation did not significantly affect the final results due to the "hidden" positions of these metal atoms), refractivity ( $R f, \AA^{3}$; the refractivity is estimated by the same method as $\log P$, presented by Ghose and Crippen [59]), and polarizability ( $\mathrm{Pol}, \AA^{3}$; this parameter was estimated according to an additive method of Miller [60], where the different increments are associated with different atom types).
Monolinear correlations (Eqs. 8a and 8b) in theoretical titanocene-cyclodextrin interaction experiments and QSARs were evaluated by using interaction energy between titanocene and cyclodextrin molecules $\left(E_{\text {int. }}\right)$ or the above mentioned $\mathrm{p} A$ cytotoxic activity and structural parameters $(P)$.

$$
\begin{aligned}
& E_{\text {int } ., i}=a_{0}+b \cdot P_{i} . \\
& p A_{i}=a_{0}+b \cdot P_{i} .
\end{aligned}
$$

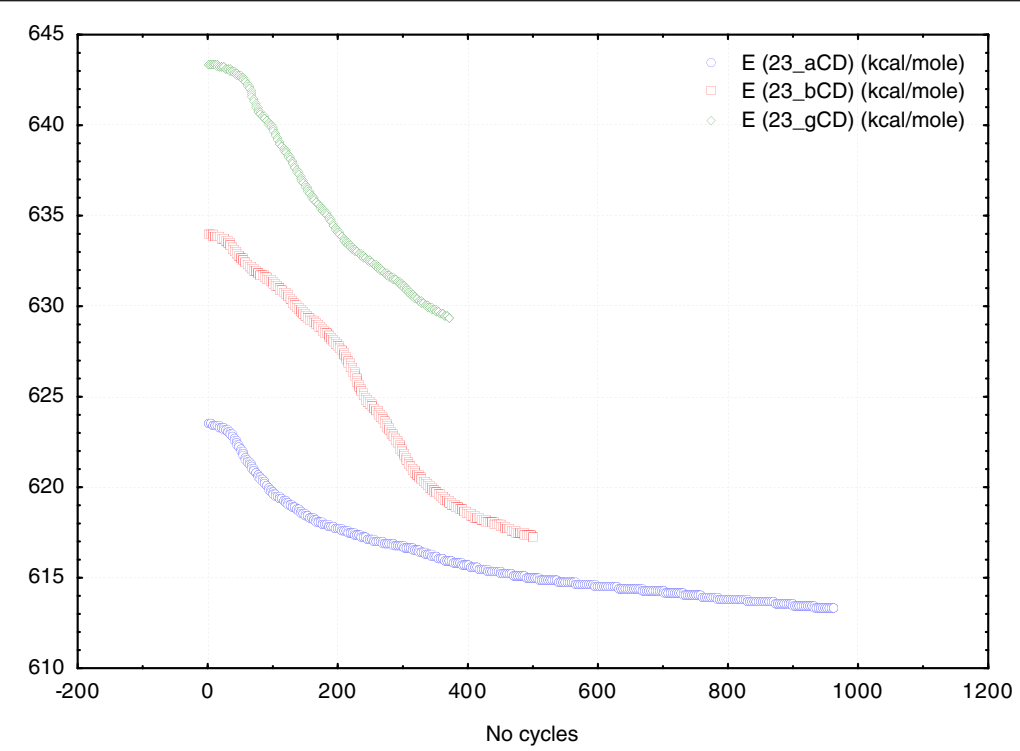

Figure 5 Interaction energy vs. Number of cycles from MM+ titanocene/cyclodextrin geometry optimization experiments for 23TC. 


\section{Additional files}

Additional file 1: Molecular modelling and complex optimization of titanocene / cyclodextrin systems. Description: In this additional file the molecular modelling of titanocenes (A1), the quantitative structureactivity relationships (QSARs), which contain correlations between experimental and predicted activities, as well as the cross-validation data (leave-half-out method) for QSARs (A2), and complex optimization of titanocene/cyclodextrin complexes (starting positions and the most stable titanocene / cyclodextrin supramolecular systems; variation of the titanocene / cyclodextrin interaction energy in the complexation process; titanocene / cyclodextrin interaction energies correlations) (A3) are presented. These data supports all considerations presented in the manuscript.

Additional file 2: Titanocene / cyclodextrin interaction energies. Description: In this additional file the interaction energy versus the number of cycles data from MM+ optimization experiments for titanocene / cyclodextrin complexation process is presented; this supports all considerations presented in the manuscript.

\section{Competing interests}

The authors declare that they have no competing interests.

\section{Authors' contributions}

$\mathrm{NGH}$ and DIH carried out all theoretical experiments and prepared the final manuscript. AR and ZG help to discuss the theoretical results. All authors read and approved the final manuscript.

\section{Acknowledgements}

This work was supported by Ministry of Education, Research, Youth, and Sports from Romania, PN2_ID_PCCE_140/2008. Authors are grateful to Professor Mircea Mracec ("Coriolan Drăgulescu" Institute of Chemistry, Timişoara, Romania) for permission to use the HyperChem 5.11 molecular modeling package.

\section{Author details}

'Department of Food Science, Banat's University of Agricultural Sciences and Veterinary Medicine, Faculty of Food Processing Technology, C. Aradului 119, Timişoara 300645, Romania. 'Department of Applied Chemistry and OrganicNatural Compounds Engineering, "Politehnica" University of Timişoara, Faculty of Industrial Chemistry and Environmental Engineering, Carol Telbisz 6, Timişoara 300001, Romania.

Received: 1 August 2012 Accepted: 15 October 2012

Published: 5 November 2012

\section{References}

1. Avendaño C, Menéndez JC: Medicinal chemistry of anticancer drugs. Amsterdam: Elsevier; 2008:1-3.

2. Quintans-Júnior L, Fagundes da Rocha R, Freitas Caregnato F, Fonseca Moreira JC, Amaral da Silva F, Antunes de Souza Araújo A, Almeida dos Santos JP, Santos Melo M, Pergentino de Sousa D, Rigoldi Bonjardim L, Pens Gelain D: Antinociceptive Action and Redox Properties of Citronellal, an Essential Oil Present in Lemongrass. J Med Food 2011, 14:630-639. doi: 10.1089/jmf.2010.0125.

3. Clapp RW, Jacobs MM, Loechler EL: Environmental and occupational causes of cancer. Lowell: The Lowell Center for Sustainable Production, University of Massachusetts; 2007:24-28.

4. Vogelstein B, Kinzler KW: The Genetic Basis of Human Cancer. New York: McGraw-Hill, Medical Publication Division; 2002.

5. Tong R, Cheng J: Anticancer polymeric nanomedicines. Polym Rev 2007, 47:345-381. doi: 10.1080/15583720701455079.

6. Andersen M, Kiel P, Larsen H, Maxild J: Mutagenic action of aromatic epoxy resins. Nature 1978, 276:391-392. doi: 10.1038/276391a0.

7. Chaudhary A, Pandeya SN, Kumar P, Sharma PP, Gupta S, Soni N, Verma KK, Bhardwaj G: Combretastatin A-4 analogs as anticancer agents. Mini Rev Med Chem 2007, 7:1186-1205. doi: 10.2174/138955707782795647.

8. Cragg GM, Kingston DGI, Newman DJ: Anticancer agents from natural products. Boca Raton: CRC Press; 2005.
9. Gasser G, Ott I, Metzler-Nolte N: Organometallic anticancer compounds. J Med Chem 2011, 54:3-25. doi: 10.1021/jm100020w.

10. Vessières A, Plamont M-A, Cabestaing C, Claffey J, Dieckmann S, Hogan M, Müller-Bunz H, Strohfeldt K, Tacke M: Proliferative and anti-proliferative effects of titanium- and iron-based metallocene anti-cancer drugs. J Organomet Chem 2009, 694:874-879. doi: 10.1016/j.jorganchem.2008.11.071.

11. Ashton PR, Balzani V, Clemente-León M, Colonna B, Credi A, Jayaraman N, Raymo FM, Stoddart JF, Venturi M: Ferrocene-containing carbohydrate dendrimers. Chem Eur J 2002, 8:673-684. doi: 10.1002/1521-3765(20020201) 8:3<673::AID-CHEM673>3.0.CO;2-D.

12. Campbell KS, Dillon CT, Smith SV, Harding MM: Radiotracer studies of the antitumor metallocene molybdocene dichloride with biomolecules. Polyhedron 2007, 26:456-459. doi: 10.1016/j.poly.2006.07.004.

13. Casas-Solvas JM, Ortiz-Salmeron E, Fernandez I, Garcia-Fuentes L, SantoyoGonzalez F, Vargas-Berenguel A: Ferrocene- $\beta$-cyclodextrin conjugates: synthesis, supramolecular behavior, and use as electrochemical sensors. Chem Eur J 2009, 15:8146-8162. doi: 10.1002/chem.200900593.

14. Chohan ZH, Sumrra SH, Youssoufi MH, Hadda TB: Metal based biologically active compounds: Design, synthesis, and antibacterial/antifungal/ cytotoxic properties of triazole-derived Schiff bases and their oxovanadium(IV) complexes. Eur J Med Chem 2010, 45:2739-2747. doi: 10.1016/j.ejmech.2010.02.053.

15. Fey N: Organometallic molecular modelling - the computational chemistry of metallocenes: a review. J Chem Technol Biotechnol 1999, 74:852-862.

16. Gómez-Ruiz S, Kaluđerović GN, Polo-Cerón D, Prashar S, Fajardo M, Zižak Z, Juranić ZD, Sabo TJ: Study of the cytotoxic activity of alkenyl-substituted ansa-titanocene complexes. Inorg Chem Commun 2007, 10:748-752. doi: 10.1016/j.inoche.2007.03.016.

17. Gómez-Ruiz S, Kaluđerović GN, Prashar S, Polo-Cerón D, Fajardo M, Zižak Z, Sabo TJ, Juranić ZD: Cytotoxic studies of substituted titanocene and ansatitanocene anticancer drugs. J Inorg Biochem 2008, 102:1558-1570. doi: 10.1016/j.jinorgbio.2008.02.001.

18. Immel TA, Martin JT, Dürr CJ, Groth U, Huhn T: Dimethyl titanocene Y: a valuable precursor for libraries of cytotoxic titanocene derivatives. J Inorg Biochem 2010, 104:863-867. doi: 10.1016/j.jinorgbio.2010.04.003.

19. Liu $Y$, Zhong $R-Q$, Zhang $H-Y$, Song $H-B$ : A unique tetramer of 4: $5 \beta$ cyclodextrin-ferrocene in the solid state. Chem Commun 2005, 17:2211-2213. doi: 10.1039/b418220k.

20. Lu Z, Lu C, Ren X, Meng Q: New metallocene-bridged cyclodextrin dimer: A stable derivative of the antitumor drug titanocene dichloride and its potent cytotoxity against human breast cancer (MCF-7) cells. J Organomet Chem 2006, 691:5895-5899. doi: 10.1016/j. jorganchem.2006.09.052.

21. Napoli M, Saturnino C, Sirignano E, Popolo A, Pinto A, Longo P: Synthesis, characterization and cytotoxicity studies of methoxy alkyl substituted metallocenes. Eur J Med Chem 2011, 46:122-128. doi: 10.1016/j. ejmech.2010.10.021.

22. Potter GD, Baird MC, Cole SPC: A new series of titanocene dichloride derivatives bearing cyclic alkylammonium groups: Assessment of their cytotoxic properties. J Organomet Chem 2007, 692:3508-3518. doi: 10.1016/j.jorganchem.2007.04.024

23. Wallis D, Claffey J, Gleeson B, Hogan M, Müller-Bunz H, Tacke M: Novel zirconocene anticancer drugs? J Organomet Chem 2009, 694:828-833. doi: 10.1016/j.jorganchem.2008.08.020.

24. Braga SS, Almeida Paz FA, Pillinger M, Seixas JD, Romão CC, Gonçalves IS: Structural studies of $\beta$-cyclodextrin and permethylated $\beta$-cyclodextrin inclusion compounds of cyclopentadienyl metal carbonyl complexes. Eur J Inorg Chem 2006, 8:1662-1669. doi: 10.1002/ejic.200501006.

25. Morales A, Weber RT, Melendez E: Spectroscopic and thermal characterization of the host-guest interactions between $\alpha$-, $\beta$ - and $\gamma$-cyclodextrins and vanadocene dichloride. Appl Organomet Chem 2008, 22:440-450. doi: 10.1002/aoc.1420.

26. Singh R, Bharti N, Madan J, Hiremath SN: Characterization of cyclodextrin inclusion complexes - a review. J Pharm Sci Technol 2010, 2:171-183.

27. Sokolov VI: Cyclodextrin-metallocene inclusion complexes. In Supramolecular stereochemistry. Edited by Siegel JS. Dordrecht: Kluwer Academic Publishers; 1995:239-245. doi: 10.1007/978-94-011-0353-4_30.

28. Brewster ME, Loftsson T: Cyclodextrins as pharmaceutical solubilizers. Adv Drug Deliv Rev 2007, 59:645-666. doi: 10.1016/j.addr.2007.05.012.

29. Hădărugă DI, Hădărugă NG, Bandur GN, Isengard H-D: Water content of flavonoid/cyclodextrin nanoparticles: relationship with the structural 
descriptors of biologically active compounds. Food Chem 2012, 132:1651-1659. doi: 10.1016/j.foodchem.2011.06.004.

30. Hădărugă DI, Hădărugă NG, Bandur GN, Riviş A, Costescu C, Ordodi V, Ardelean A: Berberis vulgaris extract/B-cyclodextrin nanoparticles: synthesis and characterization. Rev Chim 2010, 61:669-675.

31. Hădărugă DI, Hădărugă NG, Butnaru G, Tatu C, Gruia A: Bioactive microparticles (10): thermal and oxidative stability of nicotine and its complex with $\beta$-cyclodextrin. J Ind Phenom Macrocycl Chem 2010, 68:155-164. doi: 10.1007/s10847-010-9761-0.

32. Hădărugă NG, Hădărugă DI, Păunescu V, Tatu C, Ordodi VL, Bandur GN, Lupea AX: Bioactive nanoparticles (6). thermal stability of linoleic acid / a- and $\beta$-cyclodextrin complexes. Food Chem 2006, 99:500-508. doi: 10.1016/j.foodchem.2005.08.012.

33. Szejtli J, Szente L: Elimination of bitter, disgusting tastes of drugs and foods by cyclodextrins. Eur J Pharm Biopharm 2005, 61:115-125. doi: 10.1016/j.ejpb.2005.05.006.

34. Serafini MR, Menezes PP, Costa LP, Lima CM, Quintans $\sqcup J$ Jr, Cardoso JC, Matos JR, Soares-Sobrinho JL, Grangeiro S Jr, Nunes PS, et al: Interaction of p-cymene with beta-cyclodextrin. J Therm Anal Calorim 2012, 109:951-955. doi: 10.1007/s10973-011-1736-x.

35. HyperChemTM release 5.11 Professional for Windows. Gainsville, FL, USA: Hypercube, Inc; 1999. http://www.hyper.com.

36. Hansch C, Maloney PP, Fujita T, Muir RM: Correlation of biological activity of phenoxyacetic acids with Hammett substituent constants and partition coefficients. Nature 1962, 194:178-180. doi: 10.1038/194178b0.

37. Hansch C, Fujita T: p- $\sigma-\pi$ analysis. A method for the correlation of biological activity and chemical structure. J Am Chem Soc 1964, 86:1616-1626. doi: 10.1021/ja01062a035.

38. Menger FM, Sherrod MJ: Docking calculations on ferrocene complexation with cyclodextrins. J Am Chem Soc 1988, 110:8606-8611. doi: 10.1021/ ja00234a005.

39. Sherrod MJ: Exploration of cyclomalto-oligosaccharide (cyclodextrin) chemistry with molecular mechanics: Docking calculations on the complexation of ferrocenes with cyclodextrins. Carbohydr Res 1989, 192:17-32. doi: 10.1016/0008-6215(89)85161-4.

40. Duchamp DJ: Molecular mechanics and crystal structure analysis in drug design. In Computer-Assisted Drug Design. Volume 112. Edited by Olson EC, Christoffersen RE. Washington, DC: American Chemical Society; 1979:79-102. doi: 10.1021/bk-1979-0112.ch003.

41. Ulrich B, Allinger NL: Molecular mechanics. Washington: American Chemical Society; 1982.

42. Leach AR: Molecular modelling. Principles and Applications. Harlow: Pearson Education Limited; 2001

43. Hinchliffe A: Modelling molecular structures. Chichester: John Wiley \& Sons, Ltd.; 2000 .

44. Bowen JP, Allinger NL: Molecular Mechanics: The Art and Science of Parameterization. In Reviews in Computational Chemistry. Volume 2. Edited by Lipkowitz KB, Boyd DB. Hoboken, NJ: John Wiley \& Sons, Inc; 2007. doi: 10.1002/9780470125793.ch3.

45. Allinger NL, Zhou X, Bergsma J: Molecular mechanics parameters. J Mol Struct (THEOCHEM) 1994, 312:69-83. doi: 10.1016/S0166-1280(09)80008-0.

46. Jianu C: Synthesis of nonionic-anionic colloidal systems based on alkaline and ammonium $\beta$-nonylphenol polyethyleneoxy $(n=3-20)$ propionates / dodecylbenzenesulfonates with prospects for food hygiene. Chem Cent J 2012, 95. doi: 10.1186/1752-153X-6-95.

47. Doman TN, Landis CR, Bosnich B: Molecular mechanics force fields for linear metallocenes. J Am Chem Soc 1992, 114:7264-7272. doi: 10.1021/ ja00044a042.

48. Doman TN, Lollis TK, Bosnich B: Molecular mechanics force fields for bent metallocenes of the type [M(Cp)2Cl2]. J Am Chem Soc 1995, 117:13521368. doi: 10.1021/ja00109a020.

49. Timofeeva TV, Lii J-H, Allinger NL: Molecular mechanics explanation of the metallocene bent sandwich structure. J Am Chem Soc 1995, 117:7452-7459. doi: 10.1021/ja00133a018.

50. Comba P, Hambley TW: Molecular Modeling of Inorganic Compounds. Weinheim: Wiley-VCH; 2001.

51. Yao S, Shoji T, Iwamoto $Y$, Kamei E: Consideration of an activity of the metallocene catalyst by using molecular mechanics, molecular dynamics and QSAR. Comput Theor Polym Sci 1999, 9:41-46. doi: 10.1016/S1089-3156 (98)00051-8
52. Hasel W, Hendrickson TF, Still WC: A rapid approximation to the solvent accessible surface areas of atoms. Tetrahedron Comput Meth 1988, 1:103-116. doi: 10.1016/0898-5529(88)90015-2.

53. Still WC, Tempczyk A, Hawley RC, Hendrickson T: Semianalytical treatment of solvation for molecular mechanics and dynamics. J Am Chem Soc 1990, 112:6127-6129. doi: 10.1021/ja00172a038.

54. Bodor N, Gabanyi Z, Wong CK: A new method for the estimation of partition coefficient. J Am Chem Soc 1989, 111:3783. doi: 10.1021/ ja00193a003.

55. Gavezzotti A: The calculation of molecular volumes and the use of volume analysis in the investigation of structured media and of solidstate organic reactivity. J Am Chem Soc 1983, 105:5220-5225. doi: 10.1021/ ja00354a007.

56. Ooi T, Oobatake M, Némethy G, Scheraga HA: Accessible surface areas as a measure of the thermodynamic parameters of hydration of peptides. Proc Natl Acad Sci 1987, 84:3086-3090.

57. Ghose AK, Pritchett A, Crippen GM: Atomic physicochemical parameters for three dimensional structure directed quantitative structure-activity relationships III: modeling hydrophobic interaction. J Comput Chem 1988, 9:80-90. doi: 10.1002/jcc.540090111.

58. Viswanadhan VN, Ghose AK, Revankar GR, Robins RK: Atomic physicochemical parameters for three dimensional structure directed quantitative structure-activity relationships. 4. Additional parameters for hydrophobic and dispersive interactions and their application for an automated superposition of certain naturally occurring nucleoside antibiotics. J Chem Inf Comp Sci 1989, 29:163-172. doi: 10.1021/ ci00063a006

59. Ghose AK, Crippen GM: Atomic physicochemical parameters for threedimensional-structure-directed quantitative structure-activity relationships. 2. Modeling dispersive and hydrophobic interactions. J Chem Inf Comp Sci 1987, 27:21-35. doi: 10.1021/ci00053a005.

60. Miller KJ: Additivity methods in molecular polarizability. J Am Chem Soc 1990, 112:8533-8542. doi: 10.1021/ja00179a044.

doi:10.1186/1752-153X-6-129

Cite this article as: Rivis et al:: Titanocene / cyclodextrin supramolecular systems: a theoretical approach. Chemistry Central Journal 2012 6:129.

Publish with ChemistryCentral and every
scientist can read your work free of charge
"Open access provides opportunities to our
colleagues in other parts of the globe, by allowing
anyone to view the content free of charge."
W. Jeffery Hurst, The Hershey Company.
- available free of charge to the entire scientific community
- peer reviewed and published immediately upon acceptance
- cited in PubMed and archived on PubMed Central
- yours - you keep the copyright
submit your manuscript here:
http://www.chemistrycentral.com/manuscript/

